\title{
An Analysis on the Motivation Factors of Generating University Culture JIANG Xue ${ }^{1, a^{*}}$, ZHANG Dexiang $^{2}$ \\ ${ }^{1}$ Research Center for Higher Education, Dalian University of Technology, Dalian 116024, CHINA \\ ${ }^{2}$ Research Center for Higher Education, Dalian University of Technology, Dalian 116024, CHINA \\ ajiangxue@dlut.edu.cn
}

Keywords: University culture, university members, profound knowledge, environment

\begin{abstract}
University culture is a way of life produced and shared by the faculty and students of university in the process of creating, understanding, disseminating, saving, and innovating profound knowledge; It is a gradual process of congregating scattered cultural elements and form a cultural web and reach consensus. Consensus and share are the key stage to forming university culture. And university members, profound knowledge and the environment are the motivating factors.
\end{abstract}

These years, a great deal of attention has been paid to making universities better, people wants to get universities to change quickly and be more responsive to state mandates. And university culture has become a hotspot in the field of research on higher education, as people realize the culture of a school plays a central role in exemplary performance. Despite all this, the fact is relevant theoretical research is not satisfying as few mature theories of university culture have been proposed. The significance of this research is not only going to fill the theoretic blank, but also provide guidance for forming university culture in higher education institutions in our country. The accurate knowledge of the connotation, origin and forming mechanism of university culture will help understand form university culture.

This research attempts to discuss the connotation, essence, motivation, forming process and mechanism of university culture from the new perspective of theory of practice and organization culture, and propose two models of forming mechanism of university culture.

Motivation factors of generating university culture. Beneath the surface of everyday life in schools is an underground river of feelings, folkways, norms, and values that influence how people go about their daily work. This taken-for-granted set of expectations affects how people think, feel, and act. It shapes how they interpret the hundreds of daily interactions of their work lives and provides meaning and purpose for their interactions, activities, and work (Deal and Peterson, 2009). A simple way of thinking about culture is "the way we do things around here" (Bower, 1966).

Strong, positive university culture do not just happen. They are built over time by those who work in and attend the university and by the formal and informal leaders who encourage and reinforce values and traditions. Culture is the outcome of human's practical activity. Social practice is the premise and foundation of culture, and its production mode determines the type of culture. University culture is a way of life produced and shared by the university members in the process of creating, understanding, disseminating, storing, and innovating profound knowledge. It is a gradual process of congregating scattered cultural elements and shaping a cultural web and reaching consensus. It is a gradual process of generating a series of incomplete elements of objective, such as faith, value, mythology and ritual and hero, to be complete, and forming a complete university cultural web.

For a university, the practical activity of university members mainly is creating, understanding, disseminating, storing, and innovating profound knowledge. University culture is a consensus which generate during the process of adapting to external environment and integrating the internal produced by the faculty and students. The formation of university culture throughout the entire process of university's founding, developing, and transformation. The key of this research is porbing the university members' practical activity and finding the rule of shaping a cultural web. So to speak, for 
university members is the only subject of generating university cultural, profound knowledge is the object of generating university cultural, and the environment is the essential condition, as figure 1 . And university members, profound knowledge and external environment are the three elements in generating university culture which react upon one another.

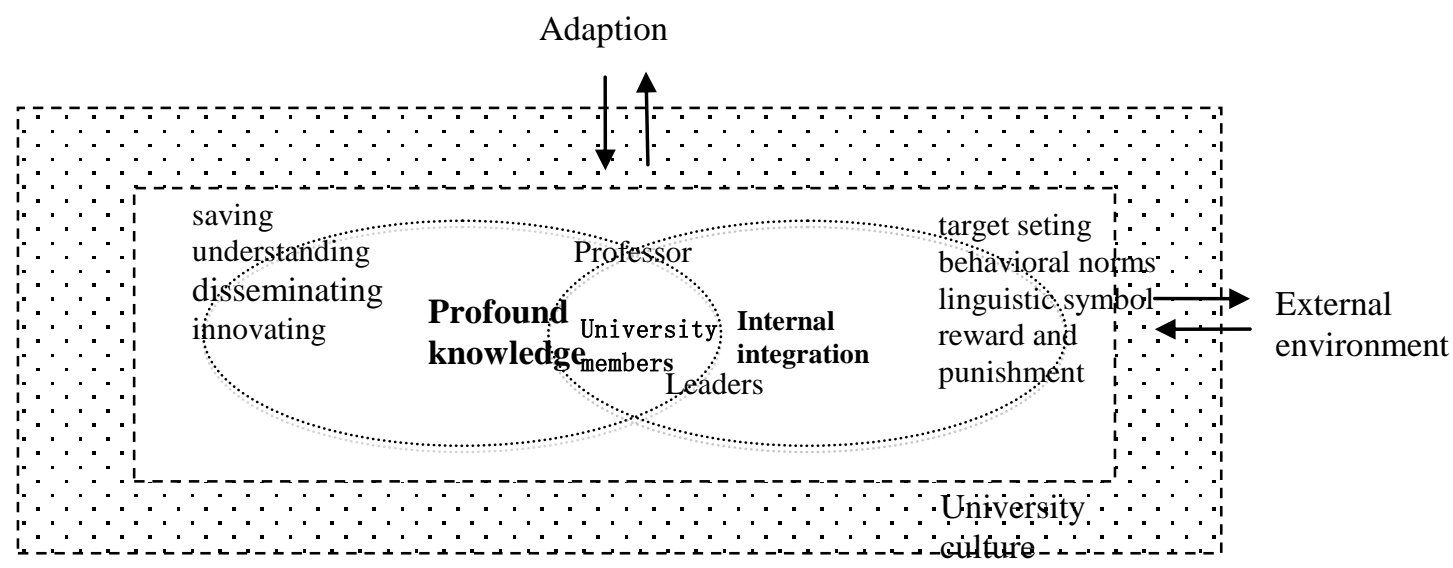

Figure 1 The generating of university culture

The creating, understanding, disseminating, saving, and innovating profound knowledge is the essence of university, but not the the pure knowledge processing process does not necessarily generate culture, which is the outcome of adapting of external and internal environment in order to be legality. University members reach a consensus in the common experience and share it as cultrue. So consensus and sharing are the key stages of forming university culture. University members, profound knowledge and the environment are the motivating factors.

In another word, it is the product of the conscious activity of university people, who are the only subject of the forming of a university culture; profound knowledge decides the uniqueness of the college culture; external environment is the essential condition

Generating mechanism of university culture. The forming of university culture is a gradual process of congregating scattered cultural elements and shape a cultural web and reach consensus. This thesis proposes to divide the forming mechanism of university culture into the dominated type and the spontaneous type, as figure 2 and figure 3.

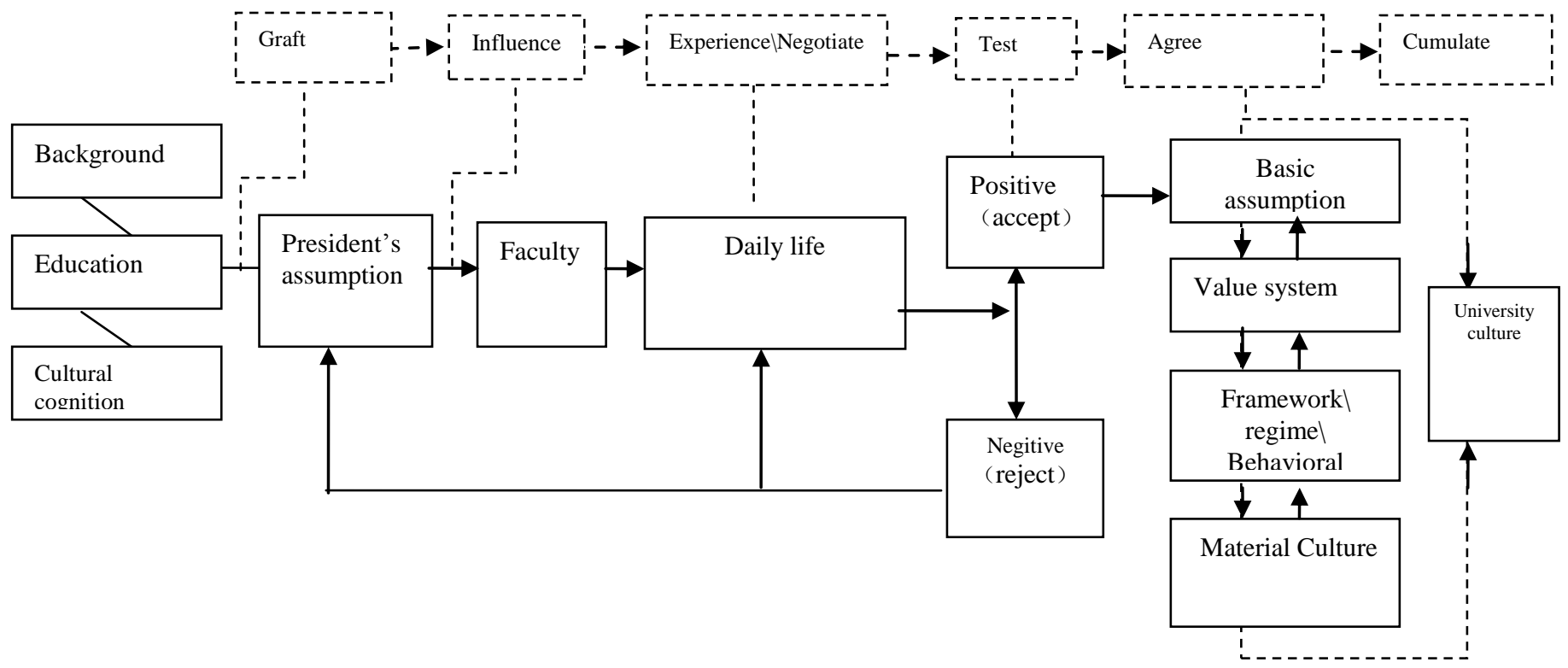

Figure 2 Dominated type of generating of university culture: GENTAC Model 


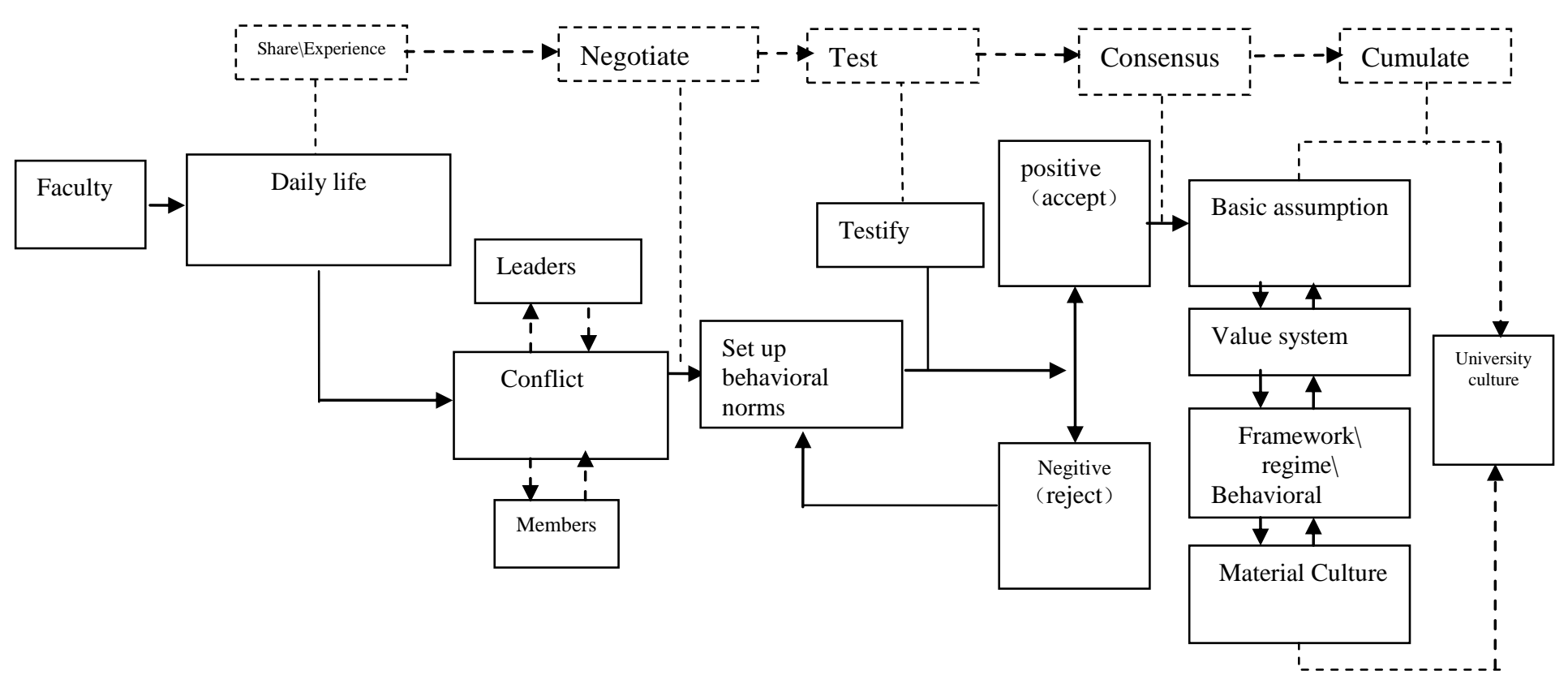

Figure 3 Spontaneous type of generating of university culture: SENTAC Model

The forming of a dominated type of university culture mainly happens with the implementation proposed and dominated by the founders and administrators of a university, while the forming of the spontaneous type of university culture originates from the self-cultivation and evolution of the faculty of a university, who has gradually improved and shaped the dominate faculty culture into the university culture by way of consultation and compromise in the daily work of a university.

Leaders are the subjects of management activity of college. They are responsible to operate the college smoothly and efficiently. University culture may directly come from founders' philosophy, values and hypotheses during the primary stage of the formation of college culture. Every outstanding college president may introduce his own philosophy and lead the college to develop along the ideal direction.

Faculty is the subjects of teaching, discovering, and applying profound knowledge. The conformable psychology makes it possible for the teacher-subject culture to develop into college culture. People have a common psychological tendency, i.e. the desire to be assigned to a large group, be accepted by the majorities, and be protected, assisted and supported by the group. The group attribute indicates that people tend to conform to the other members in the group. Therefore, college culture which represents the philosophy of the majorities is the result of the compromise and negotiation of the majorities and is an unconscious culture formation. Students are the subjects of communicating and conceiving advanced knowledge. They are the participants of practical activities and the successors of college culture. As a college student, one must have strong self-consciousness and is expected to cultivate distinctive, distinguishable and different personal culture, which is the inevitable requirement during self-development.

In conclusion, university culture is a powerful web of rituals and traditions, norms and values which affects every corner of school life. University culture influences what members pay attention to, how they identify with the university, what is important and valued, how hard they should work, and the degree to which they achieve their goals. So a positive culture improves university effectives and productivity. So the university culture is so important that nobody can avoid.

Conclusion and suggestion. This research is mainly to strengthen the awareness of university leaders to realize the three important motivating factors, university members, profound knowledge and external environment, and the two mechanism of generating university culture. But it need further research on this topic, especially the role leaders and faculty play on forming culture. 